\title{
Biochemical Parameters in Human Immunodeficiency Virus Disease Progression
}

\author{
Ramana KV ${ }^{1 *}$, Ratna Rao ${ }^{1}$, Sabitha ${ }^{2}$, Venugopal $B^{2}$ \\ 2 and Sanjeeva Rao $D^{3}$ \\ ${ }^{1}$ Apollo Health City, Jubilee hills, Hyderabad, Andhra Pradesh, India \\ ${ }^{2}$ Chalmeda Anand Rao Institute of Medical Sciences, Bommakal, Karimnagar, Andhra Pradesh, India \\ ${ }^{3}$ Prathima Institute of Medical Sciences, Karimnagar, Andhra Pradesh, India
}

\begin{abstract}
Human Immunodeficiency Virus (HIV) infection, with the complexity of disease and its progression has become a challenge to human beings. HIV infection leads to variable disease course in different people, amongst them are long term non-progressors, who survive more than 10 years after getting infected. Due to the chronicity of the disease and the extent of morbidity it causes, management of such individuals has become a challenge for physicians treating HIV infected patients. Traditionally HIV disease progression is monitored using TCD4+ cell counts and HIV/RNA viral load. Resource poor countries which cannot afford such expenses are looking forward to tests that can be done easily and are cost effective to monitor HIV disease progression and treatment response. We therefore evaluated certain biochemical parameters in both HIV seropositive treatment naive and those on HAART. Significant differences are observed in the plasma concentration of CK-MB $(p<0.01)$, AST $(p<0.05)$, LDH $(p<0.01)$, Total Cholesterol: HDL ratio were $(p<0.001)$, HDL:LDL ratio $(p<0.001), A / G$ ratio $(p<0.001), A L T(p<0.02)$, Serum Albumin $(p<0.001)$, and Serum Globulin $(p<0.001)$ levels. Serum albumin $(r=-0.191)$, Albumin:Globulin ratio $(r=-0.162)$, Total protein $(r=-0.029), \mathrm{LDH}(r=-0.264), \mathrm{CK} / \mathrm{MB}(r=-0.027), \mathrm{HDL}(r=-0.0380$ and LDL:HDL ratio $(r=$ -0.032) were found negatively correlating with TCD4+ cell counts in HIV seropositive patients who are antiretroviral therapy naive. A paired t test of various parameters before and after HAART showed significant results with TCD4+ cells $(p<0.0001), C K / M B(p=0.0451)$ and LDL:HDL ratio $(p=0.0341)$. The results reemphasize the significance of evaluating certain biochemical parameters in HIV seropositive individuals and their usefulness in the management of disease progression and treatment response.
\end{abstract}

\section{Introduction}

Human Immunodeficiency Virus (HIV) infection, with the complexity of disease and its progression has become a challenge to human beings. A UNAIDS global estimate reveals that currently 33.2 million people are living with HIV infection worldwide [1]. The good news is that incidence of HIV infection showed a steady decline throughout the world. Unavailability of an approved vaccine makes this disease a tough nut to crack. HIV infection leads to variable disease course in different people, amongst them are long term nonprogressors, who survive more than 10 years after getting infected [2]. Owing to the chronicity of the disease and the extent of morbidity it causes, management of such individuals has become a challenge for physicians treating HIV infected patients. With the advent of Highly Active Antiretroviral Therapy (HAART), the quality of HIV seropositive patients improved to a greater extent, simultaneously their morbidity and mortality has reduced significantly. Conversely previous research reports have pointed out the effects of HAART on the patients as well as stressed the need to evaluate various hematological parameters before initiating HAART therapy $[3,4]$. Studies conducted in the past have also demonstrated the role of HIV infection by itself irrespective of HAART therapy can result in the development of metabolic disorders including altered lipid metabolism [5]. Previous reports have also suggested the association of cardiovascular disease (CAD) and HAART therapy [6]. Monitoring the disease progression and the response to HAART is traditionally carried out using TCD4+ cell counts and HIV/RNA viral load. The fact that it is the poor, developing and economically weak third world countries that carry most of the burden of HIV seropositive patients, it becomes financially overburdened to acquire resources and infrastructure necessary for patient management. Considering the above said factors research is now being conducted to find some cost effective, easily performed and freely available surrogate or alternate markers that can help in assessing the HIV disease progression. In the present study we have evaluated certain biochemical parameters in HIV seropositive patients including both who are antiretroviral therapy naive and those on HAART.

\section{Materials and Methods}

The study was carried out between June 2009 to May 2010, which included 36 HIV seropositive and antiretroviral therapy naive individuals and $21 \mathrm{HIV}$ seropositive patients presently on HAART since 3-4 months attending Integrated Counseling and Testing Centre (ICTC) situated at Area hospital Siddipet were enrolled in the study. A total of 25 Normal healthy individuals are included in the study as controls. All the subjects included in the study were provided with a Proforma with details of the study and an informed and written consent was obtained. Blood samples were collected following standard laboratory procedures and stored under $-20^{\circ} \mathrm{C}$. Their HIV status was confirmed following NACO guidelines using three different ELISA methods [7]. The TCD4+ cell counts were evaluated using Flow Cytometry. Serum Albumin, Globulin, and Albumin:Globulin ratio,

*Corresponding author: K V Ramana, Research Scholar, Department of Microbology, Apollo Health City, Jubilee Hills, Hyderabad, India, Tel: 09440704234; E-mail: ramana_20021@rediffmail.com

Received December 19, 2011; Accepted January 12, 2012; Published January 14,2012

Citation: Ramana KV, Ratna Rao, Sabitha, Venugopal B, Rafi MD, et al. (2012) Biochemical Parameters in Human Immunodeficiency Virus Disease Progression. J Medical Microbiol Diagnosis 1:103. doi:10.4172/2161-0703.1000103

Copyright: (c) 2012 Ramana KV, et al. This is an open-access article distributed under the terms of the Creative Commons Attribution License, which permits unrestricted use, distribution, and reproduction in any medium, provided the original author and source are credited. 
Serum Glutamate Oxaloacetate Transaminase (SGOT), Total protein, Total cholesterol, High density Lipoproteins (HDL), Low density Lipoprotein (LDL), Lactate Dehydrogenase (LDH) and Creatine Kinase $(\mathrm{CK} / \mathrm{MB})$ were evaluated by using Diasys kits in an automatic analyzer.

\section{Results}

The results revealed a significant variation in all the parameters among the HIV seropositive patients who are antiretroviral therapy naïve when compared with normal healthy individuals. The TCD4+ cell counts and biochemical parameters showed a slight difference among the HIV seropositive patients who were HAART naive and those on HAART as shown in (Table 1). Serum albumin, Albumin: Globulin ratio, Total protein, $\mathrm{LDH}, \mathrm{CK} / \mathrm{MB}, \mathrm{HDL}$ and LDL: HDL ratio were found negatively correlating with TCD4+ cell counts in HIV seropositive patients who were antiretroviral therapy naïve. Only SGOT, CK/MB and HDL: LDL ratio negatively correlated in those who were on antiretroviral therapy as shown in (Table 2). A pared t test of all the parameter showed statistically significant results with TCD4+ cell counts, Albumin: Globulin ratio, LDH, HDL, total Cholesterol, CK/MB, LDL and HDL: LDL ratio as shown in (Table 3).

\section{Discussion}

Over the time the profile of HIV epidemic has evolved from a life threatening to chronic disease, with the availability of better drugs and thanks to some efficacious resource delivery modalities involving communities and people living with HIV infection. A revolutionary new approach in the treatment endorsed by UNAIDS and WHO, simplified HIV diagnostic technologies and gave hope for achieving universal access to prevention, care and treatment of HIV/AIDS even in resource constrained settings. This resulted in prolonging survival and quality of care for people living with HIV/AIDS. The study results show a clear picture of altered biochemical parameters in HIV seropositive patients as observed in previous report by AC Ene et al. [8] in Nigeria. The study results also confirms a recent research published by Suraya Rasheed in USA showing the involvement of HIV infection alone and with no influence of HAART can deregulate the metabolic pathways [9]. Serum albumin, Globulin, Albumin: Globulin ratio and Total protein were found to be statistically significant in HIV seropositive and HAART naive patients as observed in previous studies $[10,11]$ This observation agrees with previous study that suggested evaluation of these parameters in HIV seropositive patients before initiation of HAART therapy and regularly followed up to assess the treatment response [3]. The serum SGOT, CK/MB, LDH, Total cholesterol, Total cholesterol : HDL ratio, LDL, LDL:HDL ratio were elevated after the HAART therapy as evidenced in previous studies indicating the possible development of Cardiovascular disease (CAD) due to antiretroviral therapy [12,13]. In the event of global HIV prevalence the bulk of HIV infected individuals is carried by the sub Saharan Africa and the

\begin{tabular}{|c|c|c|c|c|c|c|}
\hline Parameter & $\begin{array}{l}\text { Normal controls } \\
\text { Mean } \pm \text { SD } \\
\quad(n=25)\end{array}$ & $\begin{array}{c}\text { HAART - Mean } \pm \text { SD } \\
(n=36)\end{array}$ & $p$ value & $\begin{array}{l}\text { HAART+ } \\
\text { Mean } \pm \text { SD } \\
(n=21)\end{array}$ & $p$ value & $\begin{array}{l}\mathrm{p} \text { value before and } \\
\text { after HAART }\end{array}$ \\
\hline CD4+ Tcells & & $382.08 \pm 124.71$ & & $78.38 \pm 21.99$ & & $<0.0001$ \\
\hline Serum Albumin & $3.72 \pm 0.53$ & $4.43 \pm 1.03$ & $=0.0025^{*}$ & $4.38 \pm 0.64$ & $=0.0004^{*}$ & $<0.0001$ \\
\hline Serum Globulin & $3.1 \pm 0.43$ & $3.28 \pm 1.37$ & $=0.5284$ & $3.25 \pm 1.05$ & $=0.5171$ & $<0.0001$ \\
\hline Albumin:Globulin & $1.12 \pm 0.19$ & $1.68 \pm 0.98$ & $=0.0076^{*}$ & $1.51 \pm 0.72$ & $=0.0124^{*}$ & $<0.0001$ \\
\hline Tot. Protein & $6.82 \pm 0.74$ & $7.62 \pm 1.16$ & $=0.0035^{*}$ & $7.60 \pm 0.90$ & $=0.0024^{*}$ & $<0.0001$ \\
\hline SGOT & $23.28 \pm 9.57$ & $38.33 \pm 35.32$ & $=0.0425^{*}$ & $37 \pm 25.20$ & $=0.0155^{*}$ & $<0.0001$ \\
\hline LDH & $339.04 \pm 48.50$ & $220.42 \pm 79.04$ & $<0.0001^{*}$ & $188.76 \pm 42.91$ & $<0.0001^{*}$ & $<0.0001$ \\
\hline $\mathrm{CK} / \mathrm{MB}$ & $15.64 \pm 4.59$ & $18.06 \pm 9.52$ & $=0.2457$ & $15.38 \pm 7.34$ & $=0.8842$ & $<0.0001$ \\
\hline Cholesterol & $161.12 \pm 23.12$ & $136.08 \pm 27.27$ & $=0.0004^{*}$ & $133.33 \pm 21.72$ & $=0.0001^{*}$ & $<0.0001$ \\
\hline $\mathrm{HDL}$ & $48.76 \pm 12.30$ & $45.89 \pm 7.05$ & $=0.2509$ & $44.05 \pm 8.44$ & $=0.1448$ & $<0.0001$ \\
\hline Cholest:HDL & $3.44 \pm 0.85$ & $3.04 \pm 0.60$ & $=0.0351^{*}$ & $3.08 \pm 0.58$ & $=0.1072$ & $<0.0001$ \\
\hline LDL & $103.12 \pm 14.38$ & $157.42 \pm 36.03$ & $<0.0001^{*}$ & $175.43 \pm 24.42$ & $<0.0001^{*}$ & $<0.0001$ \\
\hline LDL:HDL & $2.21 \pm 0.55$ & $3.48 \pm 0.94$ & $<0.0001^{*}$ & $4.11 \pm 0.99$ & $<0.0001^{*}$ & $<0.0001$ \\
\hline
\end{tabular}

*Statistically significant

Table 1: The mean, Standard deviation, p value in Normal controls, HAART naive and HAART receiving HIV seropositive patients.

\begin{tabular}{|c|c|c|c|c|}
\hline Parameter & HAART - r value & HAART- $p$ value & HAART+ $r$ value & HAART+ $p$ value \\
\hline CD4+ Tcells & & $<0.0001$ & & $<0.0001$ \\
\hline Serum Albumin & -0.191 & $<0.0001$ & 0.227 & $<0.0001$ \\
\hline Serum Globulin & 0.055 & $<0.0001$ & 0.093 & $<0.0001$ \\
\hline Albumin:Globulin & -0.162 & $<0.0001$ & 0.194 & $<0.0001$ \\
\hline Tot. Protein & -0.029 & $<0.0001$ & 0.237 & $<0.0001$ \\
\hline SGOT & 0.074 & $<0.0001$ & -0.104 & $<0.0001$ \\
\hline LDH & -0.264 & $<0.0001$ & 0.568 & $<0.0001$ \\
\hline CK/MB & -0.027 & $<0.0001$ & -0.084 & $<0.0001$ \\
\hline Cholesterol & 0.147 & $<0.0001$ & 0.451 & $<0.0001$ \\
\hline HDL & -0.038 & $<0.0001$ & 0.345 & $<0.0001$ \\
\hline Cholest:HDL & 0.125 & $<0.0001$ & 0.056 & $<0.0001$ \\
\hline LDL & -0.032 & $<0.0001$ & 0.217 & $<0.0001$ \\
\hline HDL:LDL & 0.031 & $<0.0001$ & -0.086 & $<0.0001$ \\
\hline
\end{tabular}

Table 2: The Correlation coefficient( $r$ value) and unpaired $t$ test ( $p$ value) of various parameters in relation to CD4+ Tcells in both HAART naïve and HAART receiving HIV seropositive patients. 


\begin{tabular}{|c|c|}
\hline Parameter & Paired t test \\
\hline CD4+ Tcells & $<0.0001^{*}$ \\
\hline Serum Albumin & $=0.9605$ \\
\hline Serum Globulin & $=0.9176$ \\
\hline Albumin:Globulin & $=0.4386$ \\
\hline Tot. Protein & $=0.8640$ \\
\hline SGOT & $=0.6106$ \\
\hline LDH & $=0.2388$ \\
\hline CK/MB & $=0.0451^{*}$ \\
\hline Cholesterol & $=0.2485$ \\
\hline HDL & $=0.3623$ \\
\hline Cholest:HDL & $=0.8872$ \\
\hline LDL & $=0.0867^{*}$ \\
\hline HDL:LDL & $=0.0341^{*}$ \\
\hline
\end{tabular}

*Statistically significant

Table 3: Paired t test of all the parameters before and after receiving HAART.

Indian subcontinent. The availability and affordability of HAART has dramatically reduced the mortality of HIV infected people and increased the life expectancy. The poor financial position of some third world countries makes it difficult to manage the HIV infected patients which requires costly Infrastructure to assess regularly the TCD4+ cell counts and HIV/RNA viral load. In such cases the patient management can be done and disease progression assessed by other surrogate or alternate markers which show promise as observed in the current as well as recent studies. The present study results indicate effectiveness of serum albumin, globulin, Albumin: Globulin ratio in predicting the disease stage or monitoring the disease progression in HIV infected and antiretroviral therapy naive patients. The cardiovascular profile including the serum SGOT, CK/MB, LDH, Total cholesterol, Total cholesterol: HDL ratio, LDL, and LDL: HDL ratio can be beneficial in assessing the disease progression and treatment response in HIV infected patients who were on HAART therapy. In conclusion we recommend that the Management of HIV/AIDS in the HAART era should include focusing on using our resources as effectively and efficiently as possible to maximize the benefit. The spectrum of HIV care needs to evolve in to a comprehensive primary care model that has an integrated, patient centered approach, and should be linked to specialist care where and when needed.

\section{Acknowledgement}

I express my sincere thanks to DR NTR University of Health Sciences, Vijayawada, Andhrapradesh, INDIA.

\section{References}

1. World Health Organization, United Nations Children's Fund, UNAIDS (2009). Towards universal access: scaling uppriority HIVIAIDS interventions in the health sector. Progress report 2009. Geneva, World Health Organization.

2. Langford SE, Anaaworanich J, Cooper DA (2007) Predictors of disease progression in HIVinfection: A review. AIDS Res Ther 4: 11.

3. Ramana KV, Chary J, Sabitha V, Mohanty SK, Rao R (2010) Role of Hematological and Alternate Markers in Human Immunodeficiency Virus Disease Progression. American Medical Journal 1: 84-87.

4. Chaudhary M, Kashyap B, Gautam H, Saini S, Bhalla P ( 2008) Use of surrogate markers to predict the HIV disease stage and time to initiate antiretroviral therapy in developing countries. J Int Assoc Physicians AIDS Care 7: 259-264.

5. Rasheed S, Yan JS, Lau A, Chan AS (2008) HIV replication enhances production of free fatty acids, low density lipoproteins and many key proteins involved lipid metabolism: A proteomics study. pLoS One 3: e3003.

6. Kramer AS, Lazzarotto AR, Sprinz E, Manfroi WC (2009) Metabolic abnormalities, Antiretroviral therapy and cardiovascular disease in elderly patients with HIV. Arq Bras Cardiol 93: 561-568.

7. UNGASS country progress report (2008) National AIDS Control Organisation Ministry of Health and Family Welfare India New Delhi.

8. Ene AC, Harry TO, Gadzama AA, Ajayi BB, Bintube BM, et al. (2006) Biochemical abnormalities associated with HIV-1 infection as observed in Maiduguri, North-eastern Nigeria. Research Journal of Medicine and Medical sciences 1: 82-84

9. Barbaro G (2007) Visceral fat as target of highly active antiretroviral therapyassociated metabolic syndrome. Curr Pharm Des 13: 2208-2213.

10. Ajose OA, Banjoko SO, Olasode OA, Oyegunle OA, Fakunle JB (2008) Plasma biochemical parameters as prognostic markers in HIV-1 infected patients. Research Journal of Medical Sciences 2: 163-165.

11. Olawumi HO, Olatunji PO (2006) The value of Serum Albumin in pretreatment assessment and monitoring of therapy in HIVIAIDS patients. HIV Medicine 7 : 351-355.

12. Pere D, Ignacio SL, Ramon T, Fernando L, Alberto T, et al. (2008) Dyslipidemia and cardiovascular disease risk factor management in HIV-1 infected subjects treated with HAART in Spanish VACH cohort. The Open AIDS J 2: 26-38.

13. Friis-Moller N, Reiss $P$, Sabin CA, Weber R, Monforte AA, et al. (2007) Class of antiretroviral drugs and the risk of myocardial infarction. N Engl J Med 356: 1723-1735. 